\title{
Ageing, health, and health care
}

\author{
Friedrich Breyer, ${ }^{*}$ Joan Costa-Font, ${ }^{* *}$ and Stefan Felder ${ }^{* * *}$
}

\begin{abstract}
The population in the developed world has experienced a significant increase in life expectancy over the last 50 years. Simultaneously, while the onset of comorbidities has been deferred to older age groups, health-care expenditure has grown dramatically, primarily owing to the advancement of medical technology and the expansion of individual income levels, along with population ageing in the wake of increased longevity. However, the contribution of population ageing to health expenditure growth is subject to some theoretical and empirical scrutiny. This paper takes the question of ageing and health and health care to the data to evaluate the net impact of ageing. We focus on two main questions, namely the welfare valuation of longevity improvements for various OECD countries, along with the 'red herring' hypothesis which suggests that population ageing has a small and almost negligible impact on health-care expenditure. Our estimates lead us to suggest an average gain in longevity of 4.5 years since 1980 , corresponding to about 13.5 per cent of lifetime income of a 20 -year-old in 2000 . Furthermore, we confirm a weak red-herring claim, that is, that population ageing accounts for only a 0.5 per cent annual growth rate of health-care expenditure. Finally, we find that the rise in longevity leads to a further demand for life-prolonging medical care.
\end{abstract}

Keywords: health-care expenditure, longevity, value of a statistical life, ageing, 'red herring' hypothesis

JEL classification: $\mathrm{I1}$ 0, $\mathrm{I} 12, \mathrm{O} 15$

\section{Introduction}

As a result of both low fertility and longer life expectancy, the proportion of older people is growing rapidly, yet the effects of population ageing on health and health care and vice versa are far from straightforward. In particular, the empirical identification of the pathways that explain the link between ageing and health are a black box today. Understanding the implications of this question is crucial as long as the empirical evidence on this phenomenon calls for policy adjustments to the way the health system is organized.

Between 1970 and 2000 life expectancy in the OECD increased by roughly 6 years, from 70.9 to 77.2 years. Together with the simultaneous decrease of the birth rate, this has led to a substantial increase in the share of elderly people in the OECD. Over the same period,

*Universität Konstanz and DIW Berlin, e-mail: friedrich.breyer@uni-konstanz.de

**London School of Economics and Political Science, e-mail: j.costa-font@lse.ac.uk

${ }^{* * *}$ Corresponding author; Duisburg-Essen University, e-mail: stefan.felder@uni-due.de

We are grateful to Alistair McGuire and Mike Murphy for comments and help in data gathering, as well as to the members of the journal's editorial panel, and we are thankful to Miriam Krieger for her editorial assistance. 
Figure 1: Per capita health expenditure and life expectancy in OECD countries

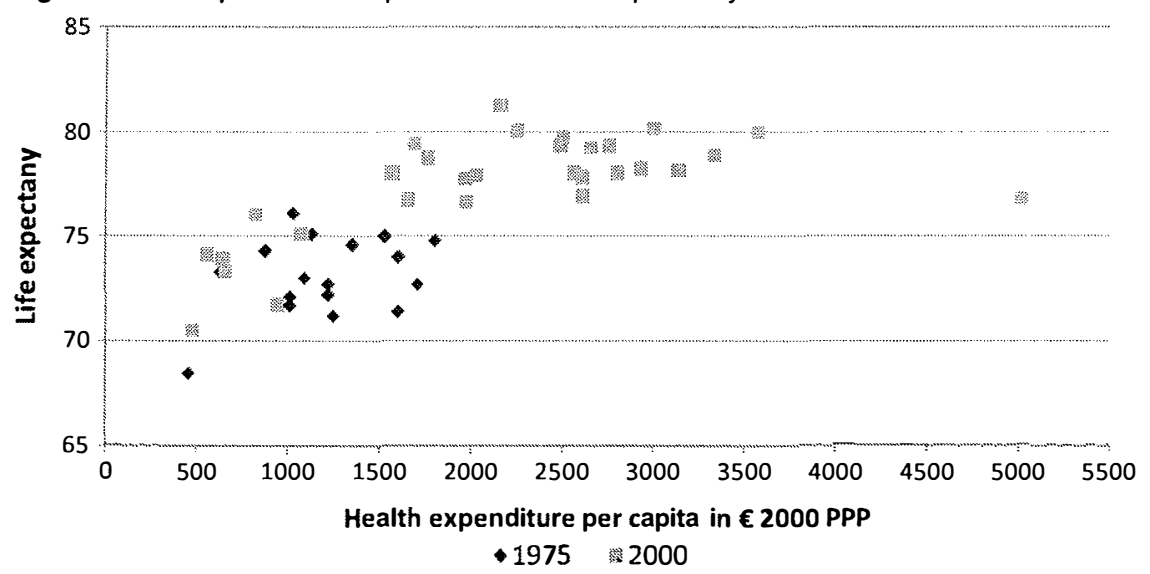

Source: OECD Health Data 2008.

per capita health-care expenditure (HCE) increased by 64 per cent, from $€ 1,290$ to $€ 2,107$ (in 2000 purchasing power parity). Figure 1 plots life expectancy against health expenditure for 20 and 30 OECD countries in 1970 and 2005. The positive correlation is evident, although it is less distinctive at high levels of HCE. Data for the year 2000 suggest that the effect of life-expectancy expansion on health expenditure is, at best, questionable.

Even when accepting that ageing and HCE are correlated, the direction of causality is far from obvious and calls for deeper understanding of its mechanisms. Some scholars, such as Hall and Jones (2007), argue that the positive relationship between HCE and life expectancy is channelled through rising income. That is, as people become richer they purchase additional years of life and less additional consumption, provided that satiation occurs more rapidly in non-health consumption than it does for consumption of health inputs. Others blame population ageing for the increase in per capita HCE (see OECD, 1988; Mendelson and Schwartz, 1993). Since HCE is a rising function of age-from the age of 60 onwards it takes the form of an almost exponentially rising curve-part of the increase of HCE might in fact be due to population ageing. Nonetheless, Zweifel et al. (1999) found that age has no effect on HCE for sub-samples of individuals aged 65 and over after controlling for proximity to death. Similarly, other studies have shown that about a quarter of overall (public and private) life-time health-care spending occurs in an individual's last year of life (Lubitz and Riley, 1993; Hogan et al., 2001).

More recently, Shang and Goldman (2007) find that age has little additional predictive power on HCE after controlling for remaining life expectancy, and even the predictive power of life expectancy declines when health status variables are included in the analysis. This result is consistent with previous findings suggesting that expected cumulative health expenditures for healthier elderly individuals, despite their greater longevity, are similar to those for less healthy persons (Lubitz et al., 1995). In turn, a recent paper by Philipson et al. (2010) argues that existing theoretical and empirical analysis undervalues near-end and particularly terminal care. Finally, while these results refer to the ageing-HCE connection, there have been many attempts, starting with Auster et al. (1969), to measure the strength of the reverse link, i.e. the productivity of health-care services in reducing mortality and 
morbidity. Furthermore, on the macro level it is desirable to measure the extent to which the observed increase in longevity can be attributed to HCE.

The purpose of this paper is twofold. First, we address the question of whether population ageing explains part of the increase of HCE and vice versa. In particular, the study draws on specific findings that qualify the association between age and HCE as a 'red herring'. This latter point is evaluated and qualified in the light of evidence fiom existing studies. Overall, we argue that ageing comes with a longevity gain and overall limited effects on health expenditure when end-of-life costs are accounted for. However, the effects of ageing are nonnegligible and come from an understanding of the causal pathways. Second, we attempt to value the effects of increased longevity drawing upon data from the OECD. The latter is performed by applying the concept of the value of life-years to these data so as to compute welfare equivalents of gains in longevity.

The paper is structured as follows. In section II we report on the increase of life expectancy in various countries of the developed world over the last 50 years. In particular, we estimate the age-specific contributions of reduced mortality to the overall increase of life expectancy, as well as the contribution of advanced medical technologies to this development. Then we address the deferment of the prevalence of comorbidity in old age under the heading of compression of morbidity. Section III deals with the so-called red herring hypothesis by Zweifel et al. (1999), which claims that population ageing is neutral with respect to the increase of HCE. Here we survey the mounting literature on this issue dating back to Fuchs (1984). We also discuss a recent study that tries to measure the impact of HCE on the rise in longevity. Section IV develops the framework for valuing improvements in longevity and applies it to Germany, the United Kingdom, Spain, and Switzerland. ${ }^{1}$ We seek to estimate the value of life-year gains between 1980 and 2000 as a percentage of lifetime wealth of a 20 -year-old in 2000 . Section $\mathrm{V}$ concludes and offers some policy implications and suggestions for further work.

\section{The compression of mortality and morbidity}

Any attempt to measure the impact of ageing on health-care use and expenditures requires adopting some assumptions on the health and life expectancy of future cohorts. If longevity results from improvements in the health status, then age-dependent future HCE will be overestimated. Therefore, assumptions on mortality and morbidity become a key feature. In this section we report on the development of age-specific mortality rates between 1950 and 2000 in Germany, the United Kingdom, Spain, and Switzerland. The data stem from the Human Mortality Database published by the Max Planck Institute, Rostock, and the University of California, Berkeley. The evaluation of the development of morbidity will be based on the general literature.

\section{(i) Compression of mortality}

To allow us to examine the patterns of mortality, Table 1 shows the change in life expectancy between 1950 and 2000 for the four countries under examination. In 1950, the Swiss and the

\footnotetext{
${ }^{1}$ We chose these countries for two reasons. First, they are sufficiently different in terms of the population's longevity and income level. Second, the authors know these countries either as citizens or residents.
} 
Table 1: Life expectancy at birth in years, 1950, 1975, 2000

\begin{tabular}{|c|c|c|c|c|c|c|c|c|}
\hline & \multicolumn{4}{|c|}{ Men } & \multicolumn{4}{|c|}{ Women } \\
\hline & 1950 & 1975 & 2000 & $1950-2000$ & 1950 & 1975 & 2000 & $1950-2000$ \\
\hline Germany & 61.20 & 68.38 & 74.75 & 13.55 & 68.53 & 74.91 & 80.54 & 12.01 \\
\hline United Kingdom & 65.75 & 71.68 & 74.94 & 9.19 & 70.43 & 74.94 & 79.72 & 9.29 \\
\hline Spain & 58.86 & 64.18 & 75.28 & 16.42 & 63.74 & 70.13 & 82.20 & 18.46 \\
\hline Switzerland & 66.16 & 71.62 & 76.45 & 10.29 & 70.60 & 75.21 & 82.11 & 11.51 \\
\hline
\end{tabular}

Source: Human Mortality Database (www.mortality.org).

Table 2: Age distribution of the gain in life expectancy in years, men, 1950-2000

\begin{tabular}{|c|c|c|c|c|c|c|c|c|}
\hline \multirow[b]{2}{*}{ Age interval } & \multicolumn{4}{|c|}{$1950-75$} & \multicolumn{4}{|c|}{$1975-2000$} \\
\hline & Germany & UK & Spain & Switzerland & Germany & UK & Spain & Switzerland \\
\hline \multicolumn{9}{|c|}{ Men } \\
\hline$<1$ & 2.91 & 1.09 & 3.52 & 1.52 & 1.14 & 0.76 & 1.11 & 0.47 \\
\hline $1-14$ & 0.63 & 0.39 & 2.27 & 0.47 & 0.34 & 0.23 & 0.29 & 0.27 \\
\hline $15-34$ & 0.69 & 0.42 & 1.91 & 0.26 & 0.61 & 0.04 & 0.07 & 0.34 \\
\hline $35-54$ & 0.66 & 0.51 & 1.45 & 0.72 & 0.78 & 0.61 & 0.26 & 0.58 \\
\hline $55-74$ & 0.67 & 0.38 & 1.23 & 0.91 & 1.92 & 2.20 & 1.43 & 1.92 \\
\hline$>75$ & 0.82 & 0.47 & 0.73 & 0.94 & 2.39 & 2.08 & 2.15 & 1.88 \\
\hline Total & 6.37 & 3.26 & 11.10 & 4.83 & 7.18 & 5.93 & 5.32 & 5.46 \\
\hline \multicolumn{9}{|c|}{ Women } \\
\hline$<1$ & 2.57 & 0.84 & 3.44 & 1.23 & 0.95 & 0.65 & 0.92 & 0.33 \\
\hline $1-14$ & 0.48 & 0.37 & 2.42 & 0.46 & 0.28 & 0.18 & 0.24 & 0.22 \\
\hline $15-34$ & 0.35 & 0.72 & 1.92 & 0.43 & 0.31 & 0.11 & 0.14 & 0.17 \\
\hline $35-54$ & 0.48 & 0.48 & 1.35 & 0.86 & 0.49 & 0.52 & 0.45 & 0.33 \\
\hline $55-74$ & 0.72 & 0.82 & 1.92 & 1.85 & 1.47 & 1.13 & 1.69 & 1.05 \\
\hline$>75$ & 1.04 & 1.55 & 1.02 & 2.07 & 2.89 & 1.92 & 2.95 & 2.50 \\
\hline Total & 5.63 & 4.78 & 12.07 & 6.90 & 6.38 & 4.51 & 6.39 & 4.61 \\
\hline
\end{tabular}

British had a substantially higher life expectancy than the Germans and the Spanish. Yet, starting off from a lower point, the populations of Germany and Spain experienced larger gains in longevity since 1950. Spanish men's life expectancy, for instance, increased by 16.4 years, whereas British men gained only 9.2 years. In all countries, men's life expectancy is about 5 years shorter than women's. Furthermore, the gender gap in longevity has shortened somewhat over time, except in Germany where it has increased by 1.5 years over the last 50 years. Overall, patterns of life expectancy reflect changes in dietary condition and health technology improvements along with other factors which are very much country specific.

Similarly, Tables 2 and 3 present the age distribution of the gains in life expectancy between 1950 and 2000. During the first 25 years, the largest contribution to the increase in life expectancy came from reduced mortality among newborns. Improvements in neonatology and paediatrics contributed between 41 per cent (Switzerland) and 56 per cent (Germany) to the increase in life expectancy of men before 1975. In the following 25 years, the decrease in mortality of newborns and children slowed down-the corresponding 
Table 3: Gain in life expectancy in years by cause of death, men and women, 1980-2000

\begin{tabular}{|c|c|c|c|c|c|c|c|c|}
\hline \multirow[b]{2}{*}{ Age interval } & \multicolumn{4}{|c|}{$1980-90$} & \multicolumn{4}{|c|}{$1990-2000$} \\
\hline & Germany & UK & Spain & Switzerland & Germany & UK & Spain & Switzerland \\
\hline \multicolumn{9}{|c|}{ Men } \\
\hline Infant mortality & 0.42 & 0.31 & 0.37 & 0.21 & 0.22 & 0.21 & 0.25 & 0.14 \\
\hline Cardiovascular diseases & 0.87 & 1.50 & 1.58 & 0.88 & 1.49 & 1.43 & 0.81 & 1.58 \\
\hline Cancer & 0.45 & 0.04 & -0.55 & 0.21 & 0.19 & 0.31 & 0.07 & 0.73 \\
\hline Diabetes & 0.04 & -0.04 & -0.02 & 0.04 & -0.05 & 0.04 & 0.02 & -0.01 \\
\hline Accidents & 0.35 & 0.19 & -0.20 & 0.17 & 0.22 & 0.09 & 0.38 & 0.72 \\
\hline Residuum & 0.60 & 0.32 & -0.15 & 0.20 & 0.56 & 0.52 & 0.92 & -0.15 \\
\hline Total & 2.73 & 2.33 & 1.02 & 1.71 & 2.62 & 2.59 & 2.45 & 3.01 \\
\hline \multicolumn{9}{|c|}{ Women } \\
\hline Infant mortality & 0.40 & 0.30 & 0.25 & 0.10 & 0.16 & 0.15 & 0.21 & 0.15 \\
\hline Cardiovascular diseases & -0.25 & 1.25 & 1.58 & -0.51 & 1.25 & 1.51 & 1.05 & 1.11 \\
\hline Cancer & 1.11 & -0.04 & -0.08 & 0.86 & 0.11 & 0.24 & 0.16 & 0.52 \\
\hline Diabetes & 0.09 & -0.03 & 0.00 & 0.08 & -0.06 & 0.06 & 0.10 & -0.01 \\
\hline Accidents & 0.19 & 0.09 & 0.03 & 0.38 & 0.16 & 0.03 & 0.11 & 0.33 \\
\hline Residuum & 0.78 & 0.35 & 0.20 & 0.95 & 0.43 & -0.26 & 0.56 & -0.20 \\
\hline Total & 2.33 & 1.93 & 1.99 & 1.85 & 2.04 & 1.72 & 2.19 & 1.90 \\
\hline
\end{tabular}

Sources: European Mortality Database; World Health Organization (WHO) (Germany, Spain); federal offices of statistics (Germany and Switzerland).

contribution to the increase in men's life expectancy ranged between 13.6 per cent (Switzerland) and 26.3 per cent (Spain), pointing to diminishing marginal returns at an already very low level of mortality. However, these results were again country specific.

Importantly, the development of mortality in the last 50 years has been markedly different for older individuals. The advancement of medical technology for the treatment of individuals older than 55 years can be argued to have contributed between 17.7 per cent (Spain) and 38.3 per cent (Switzerland) to the increase of men's life expectancy between 1950 and 1975. In the last quarter of the last century, the gains in life-years of older men contributed between 60 per cent (Germany) and 72 per cent (United Kingdom) to the total increase. In all countries, and most accentuated for the very old, life-year gains were largest in the last quarter. The latter appears to qualify as a stylized fact.

The empirical developments observed correspond to a compression of mortality. Indeed, mortality has been compressed to ever higher ages, resulting in a rectangularization of the survival curve. For a newborn, the probability of surviving the next year lies close to one up to the age of 60 , then decreases slowly before falling steeply around the age of 80 . By contrast, 50 years ago, the survival curve already decreased steadily from the age of 50 onwards.

To understand better the determinants of life expectancy it is important to analyse the main sources of mortality in each country under examination. In doing so, we find a shift in the age distribution of rising life expectancy, reflecting a clear-cut differential progress against lifethreatening ailments as displayed in Table 3 for the two decades 1980-90 and 1990-2000. The largest single contributor to life-expectancy expansion is reduced mortality from heart disease and stroke, which added between 1 and 3 years to life expectancy, with even higher 
gains for men, and occurred in the 1990s as compared to the previous decade. The large lifeyear gains of the very old, reported in Table 2, are to a great extent due to advancements in treating heart attacks and strokes. Hence, they highlight the importance of health treatment and new technologies in bringing gains in life expectancy. Furthermore, these estimates have been argued to underestimate the value of end-of-life care (Philipson et al., 2010) and thus should be treated as conservative estimates. The argument is that a self-interested individual would be willing to forgo his entire wealth to extend his life when dying, and when there is little to no value of leaving wealth behind, the value of care rises accordingly. Furthermore, Philipson et al. (2010) argue that the social value of life is larger than its private value owing to external effects on family and others.

\section{(ii) Compression of morbidity}

In addition to the compression of mortality, a second important assumption is that of the compression of morbidity. In particular, the latter hypothesis generally states that cumulative lifetime disability could be reduced if primary prevention measures postponed the onset of chronic illness and increased the average age at death, which results in turn in lower lifetime disability (Fries, 1980). In a further longitudinal analysis, Vita et al. (1998) found that the onset of disability was postponed by more than 5 years in the low-risk group as compared with the high-risk group. They concluded that smoking, body mass index (BMI), and exercise patterns in midlife and late adulthood are predictors of subsequent disability, that persons with better health habits survive longer, and that disability was postponed and compressed into fewer years at the end of life. Finally Fries (1997) found that individuals who exercised regularly developed disability at a rate of only one-fourth of that of the sedentary controls, and medical costs declined by 25 per cent compared to their controls. Crimmins (2004) finds that disability and mortality clearly decreased among elderly people in the United States during the 1990s, consistent with Cai and Lubitz (2007) who find evidence of a compression of disability in that country. Furthermore, other research goes as far as to argue that reported morbidity might be less disabling than before, owimg to health risk prevention (Crimmins and Saito, 2000; Freedman and Martin, 2000; Freedman et al., 2007).

Nonetheless, other more recent studies find that although disability measures often show improvement, an expansion of other health problems may accompany the compression of disability (Parker and Thorslund, 2007). Similarly, Lafortune et al. (2007) cast some doubts on Fries's findings by examining trends in activities of daily living (ADL) disability at age 65 and over in 12 OECD countries during the 1990s. Paradoxically, a disability decline was identified among elderly people in only five countries, namely Denmark, Finland, Italy, the Netherlands, and the United States. Three countries (Belgium, Japan, and Sweden) report an increasing disability rate and two countries (Australia and Canada) report a stable rate. Studies that examine individuals before retirement find evidence of poorer health status (Soldo et al., 2006).

Explanations of the existing heterogeneity in findings are far from evident. On the one hand, it can be argued that the expansion of education should be expected to lead to better prevention. Similarly, health technologies might have given rise to improvements in diagnosis, which make an expansion of (measured) health problems compatible with a compression of (true) disability. Recent studies looking at life expectancy without disability (e.g. Manton et al , 2006) reveal a significant compression of disability, namely an expansion 
of life free of disability, which is projected to increase from 74 per cent in 1935 to above 85 per cent in 2080.

Altogether, our findings point towards a compression of mortality, especially at older ages. The latter is underpinned by improvements in medical technologies which are likely to treat conditions that are specific to individuals in old age. Although country specific and sensitive to retirement effects, evidence suggests an expansion of life free of disability. That is, it points towards an expansion of both quality of life and life expectancy.

\section{Revisiting the red herring hypothesis}

\section{(i) The issue}

As soon as it became apparent that OECD countries are predicted to experience an expansion of the old-age population, researchers and policy analysts advising politicians started warning of the threat of exploding expenditures for health care, because in a cross-section, higher age is associated with more health-care utilization. Victor Fuchs was the first to observe that:

health care spending among the elderly is not so much a function of time since birth as it is a function of time to death. The principal reason why expenditures rise with age in cross-section (among persons aged 65 and over) is that the proportion of persons near death increases with age. (1984, pp. 151f.)

But it took one and a half decades for this relationship to be explored more thoroughly, using modern econometric techniques. In their pioneering study, Zweifel et al. (1999) analysed the HCE of roughly 1,000 persons who had died in Switzerland in the period 1983-92 and found that among those who died beyond the age of $65, \mathrm{HCE}$ in the last 8 quarters ( 2 years) of life did not depend significantly on calendar age, whereas it increased significantly with proximity to death. The authors also failed to find an age effect in years 5 to 2 before death and thus concluded: 'Exclusive emphasis on population ageing as a cause of growth in per capita HCE runs the risk of creating a red herring by distracting from the choices that ought to be made' (p. 494).

The 'red herring hypothesis' was born. It was in perfect agreement with the compressionof-morbidity thesis. If (i) the bulk of HCE occurs within a few years of severe illness leading to death, and (ii) this time span shrinks and shifts over time to ever higher ages, then population ageing is not a factor which contributes to the rise in per capita HCE.

While the Zweifel et al. (1999) study suffered from the weakness of concentrating on patients in their last 2 years of life, subsequent studies by several authors mainly confirmed the red-herring hypothesis. Felder et al. (2000) analysed a sub-sample of the data set used by Zweifel et al. (1999) and demonstrated that for persons over 65 years of age, holding time to death constant, HCE even decreased with age. Seshamani and Gray (2004a) showed that hospital costs in Britain start rising as early as 15 years before death, whereas the relationship between age and hospital costs is inversely U-shaped with a peak at age 80. Similarly, Seshamani and Gray (2004b) found a small positive effect of age on hospital costs. O'Neil et al. (2000) found no age effect on the general practitioners' costs associated with nursinghome patients when controlling for proximity to death. 
Another criticism of the Zweifel et al. (1999) methodology, raised by Salas and Raftery (2001), was that proximity to death may be endogenous if health-care interventions have a positive effect on the patient's health. This problem was addressed by Zweifel et al. (2004), who replaced the dummies for 'quarter before death' by a continuous 'time-to-death' (TTD) variable and analysed HCE in a given year as a function of TTD, age, and further variables. TTD proved to be highly significant. In this study, comprising data on roughly 90,000 Swiss persons of whom almost 96 per cent had survived the observation period by at least 42 months, the coefficients on the variables 'age' and 'age-squared' suggest a U-shaped relation between HCE and age, where the positive slope beyond age 60 seems to be more pronounced for survivors than for decedents. However, the $U$ shape might be an artefact of the quadratic specification of the regression equation. In particular, the decrease in HCE for the very old (beyond age 90) which is observed in some other studies cannot be captured with this specification.

A more thorough treatment of the endogeneity issue was carried out by Felder et al. (2010), who replaced TTD with its predicted value from an equation including HCE in the previous 3 years as regressors. They then used a regression-based Hausman test for the null hypothesis of the exogeneity of TTD, which was rejected. In the IV (instrumental variables) estimation of HCE, estimated TTD was still significantly negative, and the total effect of age remained small.

A further refinement of the analysis of age and HCE was achieved in Werblow et al. (2007). They decomposed HCE into several components and found that the age pattern of HCE not only differed considerably between survivors (with TTD > 60 months) and decedents, but even more strongly between users and non-users of long-term care (LTC). While the age profile for deceased non-users of LTC was monotonically declining, surviving non-users had a hump-shaped profile with a maximum at age 80 . On the other hand, users of LTC had an increasing age profile even for acute HCE, which is more pronounced for survivors than for decedents. These findings confer with those of Spillman and Lubitz (2000), who analysed HCE of the US Medicare population, i.e. individuals aged $65+$. They report a convex (from below) age profile for both nursing-home care and (less accentuated) for home care. By contrast, services covered by Medicare and prescription drugs exhibit a decreasing age profile. This implies a continuing shift from acute to LTC late in life. Importantly, Spillman and Lubitz conclude that population ageing will be an important driver of the demand for LTC but will leave the acute sector entirely unaffected.

\section{(ii) Forecasting future health expenditures}

While the studies summarized above all try to explain the relationship between age and HCE in past data, it may be argued that the true purpose of these exercises is to derive more solid predictions of the future development of HCE. Indeed, it was shown in several studies that, taking the TTD effect into account, expenditure forecasts become less dramatic. Stearns and Norton (2004) compared predictions of Medicare expenditures for the year 2020 on the basis of observed expenditure data from the period 1992-8, which were inferred from different regression models. They found that neglecting TTD in the regression model leads to an overestimation of the expenditure increase by 15 per cent. Polder et al. (2006) for the Netherlands found that including TTD led to a 10 per cent reduction in the growth rate of future health expenditure compared to conventional projection methods. 
confirms the hypothesis that population ageing does increase HCE through increasing life expectancy. Only the interpretation differs from the naïve one dicussed above: it is not medical need, but rather political weight that explains why an older population demands higher public spending on health care. Indeed, the increasing size of the old-age population has been argued to influence the political value of such age cohorts (Breyer and Craig, 1997).

In a recent unpublished paper, Breyer et al. (2010) used data for a pseudo-panel of all German sickness fund members (grouped by age and gender) over the period 1997-2008. In a fixed-effects regression, they found that age, mortality rate, and RLE of persons over 60 have a positive impact on per capita HCE. They then simulated future HCE in Germany on the basis of an official population forecast including life expectancy and discovered that demographic change itself is associated with an annual growth rate of roughly 0.5 per cent.

To what extent is there reverse causality between HCE and ageing-in other words, how much of the observed longevity gain is attributable to the size and growth rate of HCE? One answer is given in the Zweifel et al. (2005) paper on OECD countries discussed above. The authors, regressing remaining life expectancy at 65 on GDP, annual HCE lagged by 10 years, and other variables, found an inverse U-shaped effect of HCE on longevity which peaks well beyond average HCE for the time period. So it is safe to infer a positive impact of HCE on ageing from this study.

A recent paper by Fonseca et al. (2009) aims at quantitatively assessing the mutual dependency between HCE and longevity on the basis of a calibrated life-cycle model. A representative agent chooses consumption, medical spending, and retirement so as to maximize the discounted sum of utility flows. Earnings depend on health, which is produced using medical expenditures. The model is calibrated to US data from the period 1965-2005, and productivity growth appears as a time trend in the econometrically estimated earnings equation. The indicator for longevity used by the authors is male life expectancy at age 50 , which increased by 6.2 years over this period. Simulations show that 61 per cent of this increase ( 3.8 years) can be explained by the model, most of which ( 3 years or 48 per cent of the total increase) is due to technological change in medical care, and only less than 10 per cent is accounted for by income growth and the expansion of health insurance coverage together. These results confirm that there is mutual dependence between ageing and health expenditures.

\section{(iv) Ageing and health technologies}

An important question in this context is whether medical progress predominantly benefits the aged. If this is the case, then the findings of the previous sections (that population ageing affects HCE only weakly) must be taken with great care. One popular method to test this proposition is to look at whether age-expenditure profiles become steeper over time. A number of papers have addressed this question but the answers are diverse and therefore inconclusive.

Buchner and Wasem (2006) analysed data fiom the largest private health insurer in Germany for the period 1979-96 and defined three different indicators for a 'steepening' of the age-expenditure profile over time. In particular the increase in per capita HCE of the 'old', using 65 as the cut-off age, was significantly larger than the corresponding figure for the 'young'. Felder and Werblow (2008) challenged this result by looking at average expenditure data in the Swiss cantons over the period 1997-2006. In a panel regression with 
population averages as units of observation, the interaction effect of time and age-group dummies was not consistently increasing in age. However, for all age groups between 65 and 90 this interaction effect was positive and significant at the 10 per cent level. Thus, even for Switzerland, it cannot be ruled out that the increase in HCE has recently been particularly large in those age groups which will rapidly increase in size over the next decades.

\section{The value of increased longevity}

If individuals live longer, they will probably work longer and thus increase their lifetime income. The main effect on individual welfare, however, stems from the utility they draw from additional life-years. We attempt to evaluate empirically the expansion in longevity to gain some understanding of its overall effects. To do so, we employ the value-of-life methodology as follows. Consider the indirect utility function $V(Y, S)$ of a representative individual with lifetime income $Y$ and survival function $S$. Assume that this indirect utility function results from the solution of the following maximization problem:

$$
V(Y, S)=\max \int_{0}^{\infty} \exp (-\rho t) S(t) u(c(t)) d t
$$

subject to

$$
Y=\int_{0}^{\infty} \exp (-r t) S(t) y(t) d t=\int_{a}^{\infty} \exp (-r t) S(t)[c(t)+h(t)] d t=C+H,
$$

where $y(t)$ is income at age $t, c(t)$ is consumption at $t, h(t)$ is HCE at $t$, and $r$ and $\rho$ are the interest rate and rate of time preference. We assume that health does not enter the instantaneous utility function, but that $\mathrm{HCE}$ affects the survival function.

The survival function $S(t)$ is the probability to survive from birth to $t$

$$
S(t)=\exp \left[-\int_{0}^{t} \lambda(\tau, h(\tau)) d \tau\right]
$$

where $\lambda(\tau, h(t))$ is the instantaneous mortality (hazard) rate at $\tau$.

The value of a life is defined as the marginal rate of substitution between the hazard rate and wealth (see, among others, Arthur (1981) and Rosen (1988)). At the initial age, it amounts to

$$
L=\int_{0}^{\infty} \exp (-r t) S(t) l(t) d a
$$

where

$$
l(t)=\frac{u(c(t))}{u^{\prime}(c(t))}-c(t)-h(t)+y(t)
$$

is the instantaneous value of life. The costs in terms of consumption and HCE are subtracted from the monetary value of utility at $t$. Then life-contingent income is added to constitute the value of life per time unit. Although the concept of the value of life has been the subject of 
Table 4: Lifetime income ( $Y$ ), lifetime HCE $(H)$, and the value of life $(L)$ for 20 -year-olds in 2000 (in $€$ '000s), men and women

\begin{tabular}{|c|c|c|c|c|c|c|c|c|}
\hline & \multicolumn{2}{|c|}{ Germany } & \multicolumn{2}{|c|}{ UK } & \multicolumn{2}{|c|}{ Spain } & \multicolumn{2}{|c|}{ Switzerland } \\
\hline & Men & Women & Men & Women & Men & Women & Men & Women \\
\hline $\boldsymbol{r}$ & 1,239 & 926 & 1,389 & 812 & 800 & 573 & 1,621 & 1,217 \\
\hline$H$ & 112 & 111 & $95^{a}$ & $95^{a}$ & 77 & 77 & 141 & 161 \\
\hline$H I V$ (in \%) & 9.04 & 11.99 & 6.84 & 11.70 & 9.63 & 13.44 & 8.70 & 13.23 \\
\hline$L$ (net) & 5,044 & 3,853 & 5,903 & 3,538 & 3,242 & 2,384 & 6,906 & 5,184 \\
\hline$L$ (gross) & 5,340 & 4,219 & 6,192 & 3,788 & 3,452 & 2,648 & 7,249 & 5,654 \\
\hline
\end{tabular}

Note: ${ }^{a}$ For the UK, no differentiation of HCE for men and women was available.

Sources: Different sources.

heated debates in the economic and philosophical literatures (for a discussion see Breyer et al. (2009)), its usefulness can be seen in the fact that it goes beyond lifetime income $Y$ in the evaluation of lifetime welfare.

For the empirical analysis we restrict the utility function to the class

$$
u(c)=\frac{c^{1-\sigma}}{1-\sigma}
$$

where $\eta=-\frac{u^{\prime \prime}(c(t))}{u^{\prime}(c(t))} c$ is the (constant) elasticity of marginal utility. Under this specification (5) reduces to

$$
l(t)=\overrightarrow{1-\eta}^{c}
$$

The optimal consumption path follows $c(t)=c(0) \exp \left[\frac{r-p}{\eta} t\right]$, so that the value of life can be written as

$$
L=\int_{0}^{\infty} \exp (-r t) S(t)\left\{\exp \left[\frac{r-\rho}{\eta} t\right] \frac{\eta}{1-\eta} c(0)-h(t)+y(t)\right\} d t,
$$

where

$$
c(0)=\frac{\int_{0}^{\infty} \exp (-r t) S(t)[y(t)-h(t)] d t}{\int_{0}^{\infty} \exp [(\sigma(r-\rho)-r) t] S(t) d t}
$$

is the initial consumption level derived from the budget constraint (2).

We choose $\eta=0.8$, which implies that the monetary equivalent utility $\left(u(c) / u^{\prime}(c)\right)$ is then five times and consumer surplus $\left(u(c) / u^{\prime}(c)-c\right)$ four times the consumption level. We calculate the value of life $L$ using country-specific information on income $y(t)$ and $h(t)$ in 2000 . With respect to $y(t)$, we assume that income decreases by an annual rate equal to 3 per cent from the age 65 onwards. For the future paths we assume that wages increase by 1 per cent and HCE by 2 per cent per year. To avoid unnecessary complexities, we set both the interest rate and the discount at 3 per cent. Under these assumptions, Table 4 presents lifetime income, lifetime HCE, and the value of life for men and women in the four countries. In presenting the value-of-life estimates, we differentiate between the net value, in which HCE is deducted, and the gross value, which does not consider HCE. 
Table 4 shows the values of $Y, H$, and $L$ for men and women in the four countries. Lifetime income $Y$ of men is highest for the Swiss $(€ 1.6 \mathrm{~m})$, followed by the British $(€ 1.4 \mathrm{~m})$, the Germans $(€ 1.2 \mathrm{~m})$, and the Spanish $(€ 0.8 \mathrm{~m})$. Women earn about 25 per cent less than men, except in the United Kingdom where the difference amounts to 40 per cent. Men and women incur the same lifetime HCE; only Swiss women have a higher $H$ than men, the difference being 14 per cent. Given the lower level of human capital, women have a higher health share of income than men. This share ranges from 7 per cent (UK men) to 13 per cent (Spanish and Swiss women).

Using the latest data available at the time of the study, we estimate that the gross value of life is highest in Switzerland ( $€ 7.2 \mathrm{~m}$ for men and $€ 5.7 \mathrm{~m}$ for women) and lowest for Spain $(€ 3.5 \mathrm{~m}$ and $€ 2.6 \mathrm{~m})$. In view of the pertinent literature-Viscusi and Aldy's (2003) survey offers a range of $\$ 5.5-7.5 \mathrm{~m}$ - this range of the value of life seems reasonable. When we net out HCE, the resulting value of life decreases by about 5 and 9 per cent for men and women, respectively. Furthermore, we find that the larger reduction for women is explained by their higher health expenditure share of income.

To assess the value of longevity gain due to a change in the survival function (3), we implement a compensating variation approach. When evaluating the change in the survival function between 1980, 1990, and 2000, we always use $y(t)$ and $h(t)$ of the individual making a consumption choice in 2000 .

The results of the calculations are presented in Table 5. Over the two decades, the gross value of longevity gain ranges between $€ 62,000$ (referring to women in Spain) and $€ 253,000$ (which refers to men in Switzerland). In relative terms, the gains were highest for men in Germany (19.31 per cent) and lowest for women in the United Kingdom ( 7.82 per cent). The average increase of life expectancy for men and women is 4.5 years and the welfare gains as a percentage of lifetime income equal 13.5 per cent. These figures serve to show that the gains of increased longevity are important. For older individuals, whose lifeyear gains relative to residual life expectancy have been exceptional in the last two decades, the value of increased longevity is even larger.

The last row in Table 5 displays the values per life-years gained for men and women in the different countries. The interpretation of the results suggests that smaller longevity gains and lower income lead to substantially smaller values of life-years for women as compared to men. It is noteworthy that the average UK figure is not too far from the $£ 30,000$ threshold for a quality-adjusted life-year the National Institute for Health and Clinical Excellence (NICE) uses as a cost-effectiveness criterion to reimburse new health technologies.

Whether expenditure to sustain and prolong life would pass a cost-benefit test in the different countries depends on the marginal cost of producing an additional life-year, which we cannot calculate with aggregate data. Hall and Jones (2007) derived marginal cost per life-year well below the $\$ 100,000$ threshold they regard as reasonable for the value per year, and concluded that it would be worthwhile in the US to increase the already large GDP share of health even further. For Switzerland, the country with the second highest GDP share of health, Felder and Werblow (2009) calculated marginal cost of a life-year at about $€ 35,000$, which is below the average value per life-year in Table 5. In their analysis, marginal cost per life-year is more than three times larger for women than for men, implying that a cost-benefit test of women's average HCE would fail. 
Table 5: The value of longevity gain in absolute (in $€^{\prime} 000$ s) and relative terms (as a percentage of $y$ )

\begin{tabular}{|c|c|c|c|c|c|}
\hline & & \multicolumn{2}{|c|}{ Germany } & \multicolumn{2}{|c|}{ UK } \\
\hline & & Men & Women & Men & Women \\
\hline \multirow[t]{2}{*}{$1980-90$} & net & 103 (8.28\%) & $44(4.76 \%)$ & 77 (5.57\%) & $22(2.67 \%)$ \\
\hline & gross & 121 (9.75\%) & $60(6.51 \%)$ & $91(6.56 \%)$ & 35 (4.28\%) \\
\hline \multirow[t]{2}{*}{$1990-2000$} & net & $97(7.80 \%)$ & 36 (3.93\%) & 77 (5.55\%) & $16(1.95 \%)$ \\
\hline & gross & 118 (9.56\%) & $53(5.71 \%)$ & $95(6.84)$ & 29 (3.55\%) \\
\hline \multirow[t]{4}{*}{$1980-2000$} & net & 199 (16.07\%) & $81(8.69 \%)$ & $156(11.12 \%)$ & $38(4.62 \%)$ \\
\hline & gross & 239 (19.31\%) & $113(12.23 \%)$ & $186(13.4 \%)$ & 64 (7.82\%) \\
\hline & & \multicolumn{2}{|c|}{ Spain } & \multicolumn{2}{|c|}{ Switzerland } \\
\hline & & Men & Women & Men & Women \\
\hline \multirow[t]{2}{*}{$1980-90$} & net & $11(1.39 \%)$ & $18(3.08 \%)$ & $61(3.77 \%)$ & 38 (3.11\%) \\
\hline & gross & $16(2.06 \%)$ & 28 (4.94\%) & 77 (4.78\%) & $61(5.01 \%)$ \\
\hline \multirow[t]{2}{*}{$1990-2000$} & net & 63 (7.85\%) & $22(3.77 \%)$ & $145(8.97 \%)$ & 35 (2.89\%) \\
\hline & gross & 75 (9.40\%) & 33 (5.83\%) & $176(10.85 \%)$ & $59(4.82 \%)$ \\
\hline \multirow[t]{2}{*}{$1980-2000$} & net & 65 (8.13\%) & 39 (6.85\%) & $206(12.74 \%)$ & 73 (6.01\%) \\
\hline & gross & 77 (9.56\%) & $62(10.78 \%)$ & $253(15.63 \%)$ & $120(9.83 \%)$ \\
\hline
\end{tabular}

\section{Conclusion}

This paper has sought to examine the influence of ageing on health care, and particularly health expenditures. Our findings are consistent with the thesis that there exist marked welfare gains from life expectancy expansion, though ageing affects health expenditures through a number of different channels, some of which we manage to highlight. However, we argue that estimates are limited by causality constraints, particularly resulting from the fact that ageing itself is partly the result of rising health expenditures in the past. Also, one cannot rule out that ageing motivates innovation in expanding quality and life expectancy. It does influence the private and social value of an additional year of life, it influences expectations, and, more importantly, population ageing exerts an influence on the political prioritization of ageing-related demands.

Our estimates presented in section II show that gains in (healthy) life expectancy achieved in the last three decades have mainly accrued to the already old, and there are clear indications of a compression of both morbidity and mortality to ever higher age brackets. Against the backdrop that ageing on the whole is a factor that will moderate the growth of HCE via technological progress in medicine, we find that the rise in longevity leads to a further demand for life-prolonging medical care. Moreover, as ever more people reach a very high age (beyond 85 or 90), the percentage needing long-term care in their last years of life increases (Costa-Font et al., 2008; Costa-Font, 2010, this issue), which calls for an expansion of social but also medical components of care for the elderly, which some studies regard as conveying a high private and social value (Philipson et al., 2010)

On the whole, we find a small positive effect of ageing on per capita health expenditures, which is estimated by several studies to be in the order of an annual growth rate of one-half per cent, as evidenced in section III. This finding provides additional evidence that, while ageing in itself is not a negligible determinant of health expenditure, its ultimate effect is moderate. As section IV has made clear, with growing per capita income, the willingness to 
pay for greater longevity and, in turn, the demand for health services in old age expands. This can be predicated to result in a higher probability of using new technologies and accordingly an expansion of HCE. Hence, the traditional separation between ageing and technology use that some studies establish (Newhouse, 1992) as underpinning drivers of health expenditures is artificial. All in all, the debate on ageing and, more particularly, the 'red herring' might be summarized as follows: while ageing can not be acquitted altogether of causing a rise in health expenditures, it is far from clear that this should be considered a crime.

\section{References}

Arthur, W. B. (1981), 'The Economics of Risks to Life', American Economic Review, 71(1), 54-64.

Auster, R., Leveson, I., and Sarachek, D. (1969), 'The Production of Health, an Exploratory Study', Journal of Human Resources, 4, 411-36.

Breyer, F., and Craig, B. (1997), 'Voting on Social Security: Evidence from OECD Countries', European Journal of Political Economy, 13, 705-24.

- Felder, S. (2006), 'Life-expectancy and Health Care Expenditures: A New Calculation for Germany Dsing the Costs of Dying', Health Policy, 75(2), 178-86.

- Kifinann, M., and Zweifel, P. (2009), Health Economics, 2nd edn, Berlin and Heidelberg, Springer.

- Lorenz, N., and Niebel, T. (2010), 'Population Ageing and Health Care Expenditures: A New Test for Germany', University of Konstanz, mimeo.

Buchner, F., and Wasem, J. (2006), “'Steeping”' of Health Expenditure Profiles', The Geneva Papers on Risk and Insurance: Issues and Practice, 31(4), 581-99.

Cai, L., and Lubitz, J. (2007), 'Was there Compression of Disability for Older American from 1992 to 2003?', Demography, 44(3), 479-95.

Callahan, D. (1987), Setting Limits: Medical Goals in an Aging Society, New York, Simon and Schuster.

Costa-Font, J. (2010), 'Family Ties and Long-term Care Insurance Crowding Out', Oxford Review of Economic Policy, 26(4), 691-712.

- et al. (2008) 'Projecting Long-term Care Expenditure in Four European Union Member States: The Influence of Demographic Scenarios', Social Indicators Research, 86(2), 303--21.

Crimmins, E. M. (2004), 'Trends in the Health of the Elderly', Annual Review of Public Health, 25(10), 79-98.

- Saito, Y. (2000), 'Changes in the Prevalence of Diseases among Older Americans: 1984-1994', Demographic Research, 3(9).

Daniels, N. (1985), Just Health Care, Cambridge, Cambridge University Press.

Felder, S., and Werblow, A. (2008), 'Do the Age Profiles of Health Care Expenditure Really Steepen over Time? New Evidence from Swiss Cantons', The Geneva Papers on Risk and Insurance: Issues and Practice. Special Issue on Health Insurance, 33(4), 710-27.

- - (2009), 'The Marginal Cost of Saving a Life in Health Care: Age, Gender and Regional Differences in Switzerland', Swiss Journal of Economics and Statistics, 145(2), 137-53.

- Meier, M., and Schmitt, H. (2000), 'Health Care Expenditure in the Last Months of Life', Journal of Health Economics, 19(5), 679-95.

- Werblow, A., and Zweifel, P. (2010), 'Do Red Herrings Swim in Circles? Controlling for the Endogeneity of Time to Death', Journal of Health Economics, 29(2), 205-12.

Fonseca, R., Michaud, P.-C., Galama, T., and Kapteyn, A. (2009), 'On the Rise of Health Spending and Longevity’, Netspar Discussion Paper 12/2009-040.

Freedman, V. A., and Martin, L. G. (2000), 'Contribution of Chronic Conditions to Aggregate Changes in Old-age Functioning', American Journal of Public Health, 90(11), 1755-60.

- Schoeni, R. F., Martin, L. G., and Cornman, J. C. (2007), 'Chronic Conditions and the Decline in Late-life Disability', Demography, 44(3), 459-77.

Fries, J. F. (1980), 'Ageing, Natural Death, and the Compression of Morbidity', New England Journal of Medicine, 303(3), 130-6. 
Fries, J. F. (1997), 'Exercise and the Health of the Elderly', American Journal of Geriatric Cardiology, 6(3), 24-32.

Fuchs, V. R. (1984), 'Though Much is Taken: Reflections on Aging, Health and Medical Care', Milbank Memorial Fund Quarterly/Health and Society, 62(2), 143-66.

Hall, R. E., and Jones, C. I. (2007), 'The Value of Life and the Rise in Health Spending', Quarterly Journal of Economics, 122(1), 39-72.

Hogan, C., Lunney, J., Gabel, J., and Lynn, J. (2001), 'Medicare Beneficiaries' Cost of Care in the Last Year of Life', Health Affairs, 20(4), 188-95.

Lafortune, G., Balestat, G. the Disability Study Expert Group Members (2007), 'Trends in Severe Disability among Elderly People: Assessing the Evidence in 12 OECD Countries and Future Implications', OECD Health Working Papers No. 26, Paris, Organization for Economic Cooperation and Development.

Lubitz, J. D., and Riley, G. F. (1993), 'Trends in Medicare payments in the Last Year of Life', New England Journal of Medicine, 328(15), 1092-6.

- Beebe, J., and Baker, C. (1995), 'Longevity and Medicare Expenditure', New England Journal of Medicine, 332(15), 999-1003.

Manton, K. G., Gu, X., and Lamb, V. L. (2006), 'Long-term Trends in Life-expectancy and Active Lifeexpectancy in the United States', Population Development Review, 32(1), 81-106.

Mendelson, D. N., and Schwartz, W. B. (1993), 'The Effects of Aging and Population Growth on Health Care Costs', Health Affairs, 12(1), 119-25.

Newhouse, J. P. (1992), 'Medical Care Costs: How Much Welfare Loss?', Journal of Economic Perspectives, 6(3), 3-21.

OECD (1988), Ageing Population: the Social Policy Implications, Paris, Organization for Economic Cooperation and Development.

O’Neill, C., Groom, L., Avery, A. J., Boot, D., and Thornhill, K. (2000), 'Age and Proximity to Death as Predictors of GP Care Costs: Results from a Study of Nursing Home Patients', Health Economics, 9(8), $733-8$.

Parker, M. G., and Thorslund, M. (2007), 'Health Trends in the Elderly Population: Getting Better and Getting Worse', The Gerontologist, 47(2), 150-8.

Philipson, T. J., Becker, G., Goldman, D., and Murphy, K. M. (2010), 'Terminal Care and the Value of Life near Its End', NBER Working Paper No. 15649.

Polder, J. J., Barendregt, J. J., and van Oers, H. (2006), 'Health Care Costs in the Last Year of Life-The Dutch Experience', Social Science and Medicine, 63(7), 1720-31.

Rosen, S. (1988), 'The Value of Changes in Life Expectancy', Journal of Risk and Uncertainty, 1, 285-304.

Salas, C., and Raftery, J. P. (2001), 'Econometric Issues in Testing the Age Neutrality of Health Care Expenditure', Health Economics, 10(7), 669-71.

Seshamani, M., and Gray, A. (2004a), 'Ageing and Health Care Expenditure: the Red Herring Argument Revisited', Health Economics, 13(4), 303-314.

- (2004b), 'A Longitudinal Study of the Effects of Age and Time to Death on Hospital Costs', Journal of Health Economics, 23(2), 217-35.

Shang, B., and Goldman, D. (2007), 'Does Age or Life-expectancy Better Predict Health Care Expenditures?', Health Economics, 17(4), 487-501.

Soldo, B. J., Mitchell, O. S., Tfaily, R., and McCabe, J. (2006), 'Cross-cohort Differences in Health on the Verge of Retirement', NBER Working Paper No. 12762.

Spillman, B. C., and Lubitz, J. (2000), 'The Effect of Longevity on Spending for Acute and Long-term Care', New England Journal of Medicine, 342(19), 1409-15.

Stearns, S. C., and Norton, E. C. (2004), 'Time to Include Time to Death? The Future of Health Care Expenditure Predictions', Health Economics, 13(4), 315-27.

Steinmann, L., Telser, H., and Zweifel, P. (2007), 'Aging and Future Health Care Expenditure: A Consistent Approach', Forum for Health Economics and Policy, 10(2), 1-30.

Strech, D., Synofzik, M., and Marckmann, G. (2008), 'How Physicians Allocate Scarce Resources at the Bedside: A Systematic Review of Qualitative Studies', Journal of Medicine and Philosophy, 33(1), 80-99. 
Viscusi, W. K., and Aldy, J. E. (2003), 'The Value of Saving a Life: A Critical Review of Market Estimates Throughout the World', Journal of Risk and Uncertainty, 27(1), 5-76.

Vita, A. J., Terry, R. B., Hubert, H. B., and Fries, J. F. (1998), 'Aging, Health Risks and Cumulative Disability', New England Journal of Medicine, 338(15), 1035-41.

Werblow, A., Felder, S., and Zweifel, P. (2007), 'Population Ageing and Health Care Expenditure: A School of '"Red Herrings"'?', Health Economics, 16(10), 1109-26.

Zweifel, P., Felder, S., and Meier, M. (1999), 'Ageing of Population and Health Care Expenditure: A Red Herring?', Health Economics, 8(6), 485-96.

- Werblow, A. (2004), 'Population Ageing and Health Care Expenditure: New Evidence on the "Red Herrings",', The Geneva Papers on Risk and Insurance, 29(4), 652-66.

- Steinmann, L., and Eugster, P. (2005), 'The Sisyphus Syndrome in Health Revisited', International Journal of Health Care Economics and Financing, 5(2), 127-45. 
Breyer and Felder (2006) applied the estimated regression coefficients derived by Zweifel et al. (2004) to the projections of the age structure and mortality rates for the German population between 2002 and 2050 as published by the Federal Statistical Office. They found that compared to a 'naïve' projection which uses the unadjusted age-expenditure profile, distinguishing explicitly between survivors' and decedents' HCE dampens the projected increase up until 2050 by roughly 20 per cent. Adding a 'compression-of-morbidity' assumption-which states that if life expectancy increases between 2002 and 2050 by $x$ years, then, for example, a 65 -year-old person in 2050 will be as healthy as a 65 -minus- $x$ year-old in 2002 - lowers the expenditure projection by another 20 per cent. The surprising result of this exercise is that, even accepting the red-herring assumptions, there will still be a sizeable demographic effect on HCE. This result was confirmed by Steinmann et al. (2007), who calculated that taking the mortality effect into account lowers the forecast of the purely demographic effect on HCE in Switzerland between 2000 and 2030 from an annual growth rate of 0.7 per cent to 0.5 per cent. Still, the analysis agrees that there is a positive, although small effect of population ageing on HCE.

\section{(iii) The role of increasing life expectancy and reverse causality}

An important weakness of almost all studies in the literature summarized above is their reliance on cross-section expenditure data. Therefore, in drawing inferences from these studies for the development of HCE over time, proponents of the red-herring hypothesis are potentially subject to the same error of which they accuse their opponents (i.e. those who believe that ageing increases health spending because per capita expenditures increase with age). In particular, they overlook the fact that increasing longevity not only means that 30 years from now average age at death will be higher, but at the same time people of a certain age (say, 75) will on average have more years to live than present 75 -year olds. As a consequence, future physicians will look at 75-year old patients with different eyes than present physicians do because the notion of a 'normal life-span' will have shifted upwards. The latter has to do with technological change alongside social expectation based on updates of medical knowledge. This effect is consistent with the ethical justification of age-based rationing of health-care services (Daniels, 1985; Callahan, 1987) and with the corresponding empirical literature which shows that some physicians do, indeed, use age as a criterion in allocating scarce health-care resources (for an overview, see Strech et al., 2008).

Thus, to address the crucial question of how HCE will react to population ageing, i.e. an increase in life expectancy, econometric estimation of the determinants of HCE has to be modified in two directions: first, by looking at panel rather than cross-section data; and second, by including a direct measure of remaining life expectancy (RLE) as a regressor. Of course this cannot be done with individual data but requires an estimation with population group averages as units of observation. This approach has only been followed by two studies. The first one is Zweifel et al. (2005) which addressed the 'Sisyphus Syndrome' in health care, i.e. the mutual reinforcement of population ageing and public spending on health care of the elderly, by looking at a panel of OECD countries for the period 1970-2000. Unfortunately, life expectancy is not used as such, but a new variable, SISYPH, is created that is the product of remaining life expectancy at 60 (more precisely, the mean value for both genders) and the share of the population older than 65 . It turns out that this variable is a significant and positive determinant of health expenditures as a share of GDP, which 